\title{
Prospective study of early and late outcomes of extremely low birthweight in Central Saudi Arabia
}

\author{
Mostafa A. Abolfotouh ${ }^{1 *}$ (D) Saif Al Saif ${ }^{2}$, Waleed A. Altwaijri ${ }^{2}$ and Mohammed A. Al Rowaily ${ }^{2}$
}

\begin{abstract}
Background: Survival of preterm neonates has steadily improved over the past five decades, due to changes in the neonatal intensive care. However, in Saudi Arabia, there are no written guidelines on the definition of the lower limit of viability, and there has been a call for such a limit. The aims of this study were: (1) to determine lower limits of viability and survival in extremely low birthweight (ELBW) infants, and (2) to determine incidence of neurodevelopmental and cognitive abnormalities within 3-6 years after birth.

Methods: Prospective study of all live inborn ELBW infants admitted to the neonatal unit of King Abdulaziz Medical City, Riyadh, Saudi Arabia, within 3 years [between January 1st, 2005 and December 31st, 2007] was conducted $(n=117)$. Data were collected on demographic and birth data, neonatal complications \& interventions and death on discharge. Prospective follow up of all survivors was done, within 6 years after birth, to assess the outcome in terms of neurodevelopmental and cognitive abnormalities. Predictors of survival were determined using logistic regression model. Significance was considered at $p$-value $\leq 0.05$.

Results: Of all ELBW infants, $41 \%$ died before discharge. Survival rate was directly correlated with gestational age (GA) and birthweight $(p<0.05)$. The $50 \%$ limits of viability were those at 25 weeks' gestation or with $>600 \mathrm{~g}$. After adjusting for possible confounders, significant predictors of survival were birthweight $(p=0.001)$ and Apgar score $(p<0.001)$. The following impairments were reported during follow up of survivors: developmental delay (39.2\%), cerebral palsy (36.2\%), speech problems (33.3\%), wasting (12.5\%), intellectual disability (10\%), visual problems (6.6\%) and hyperactivity (5.6\%).

Conclusion: More than one-third of ELBW died before discharge from NICU, and two-thirds of survivors had one or more neurodevelopmental and/or cognitive abnormalities during their first 6 years of life. The $50 \%$ limits of viability of ELBW infants were those at week 25 of gestation or with a birthweight of more than $600 \mathrm{~g}$. Birthweight could be considered as more valid than gestational age in the prediction of viability of ELBW infants. The process of care of ELBW infants in Saudi Arabia may need to be revisited taking these findings into consideration.
\end{abstract}

\section{Background}

Over the past five decades, mortality of preterm neonates has steadily decreased [1-4]. The $50 \%$ limits of viability of infants has decreased to 23 to 24 weeks during this decade as compared to 30 to 31 weeks in the 1960s [4] This improvement in survival might be due to the changes in the methodologies of neonatal intensive care, new modes of respiratory support for neonates

\footnotetext{
* Correspondence: mabolfotouh@gmail.com; http://kaimrc.med.sa/ ${ }^{1}$ Research Training and Development Section, King Abdullah International Medical Research Center, King Saud bin-Abdulaziz University for Health Sciences - Ministry of National Guard-Health Affairs, Riyadh, Saudi Arabia Full list of author information is available at the end of the article
}

with respiratory distress, and development of a safety culture with the training of clinicians to work together in this culture [5].

Very preterm neonates showed significant improvement in the neurodevelopmental outcome over this period, yet this improvement lagged behind that of survival $[1,2,4-6]$. Cognitive and neurologic impairments were common among extremely preterm children at school age, as compared with their classroom peers $[7,8]$. Long-term health and educational needs were required at the age of 8 years, for ELBW who were born in the 1990s [9]. Those ELBW infants, when examined for cognitive and behavioral outcomes at school age,

(c) The Author(s). 2018 Open Access This article is distributed under the terms of the Creative Commons Attribution 4.0 International License (http://creativecommons.org/licenses/by/4.0/), which permits unrestricted use, distribution, and 
showed an IQ that was nearly two-thirds SD below that of healthy controls [10].

Very preterm infants are influenced by multiple factors that affect their survival and long-term neurodevelopmental outcome. Those who are born at large perinatal-neonatal centers, have survival advantage, because of the availability of health care providers who have vast experience in providing perinatal and neonatal care as well as comprehensive multidisciplinary operational structure $[4,11]$.

The lower limit of viability was set as 22 weeks of gestational age (GA) or $500 \mathrm{~g}$ birth weight, by the WHO [12], 22 completed weeks (154 days) gestation and ending 7 complete days after birth, by the International Classification of Diseases [13], 22 completed weeks of gestation, (instead of 24 weeks), by the Eugenic Protection Act in Japan [14] and 23 weeks GA and/or $400 \mathrm{~g}$ in birthweight, by the American Academy of Pediatrics [15]. These amendments may encourage physicians to fully resuscitate these infants at the delivery room without considering the high mortality and morbidity [16].

In Saudi Arabia, there are no written guidelines on the definition of the lower limit of viability, and there has been a call for such limit [16]. Obstetric measures for the prevention of preterm delivery need to be optimized in order to decrease the morbidity and mortality associated with extremely low birthweight infants. To achieve this goal, the outcome of extremely low birth weight Saudi infants should be understood. This study aimed to determine the survival rate of extremely low birthweight infants delivered at King Abdulaziz Medical City (KAMC), at different values of birth weight and gestational age, to determine the lower limit of viability and survival outcome, and to determine the incidence of neurodevelopmental impairments and cognitive abnormalities 3 to 6 years after birth.

\section{Methods}

\section{Study setting}

The Neonatology Section with 40 ventilated NICU beds is considered the largest section in the Pediatric Department at KAMC. It provides a high standard of care for high risk newborn infants free of charge. Neonatal services consist of the care in NICU, and can accommodate up to 40 beds (LEVEL III) and 30 beds in ICN (LEVEL II). Admission Nursery can accommodate up to 50 beds, all operated with full capacity. The NICU accepts 23 weeks gestation to term infants requiring level II and III specialized care. The Neonatal Team consists of six consultants, two assistant consultants, ten staff physicians, two Perinatal-Neonatal fellows, and three rotating pediatrics residents. A total of $140 \mathrm{NICU}$ well trained and skilful nurses are available, with a nurse to patient ratio of 1:1-2. It provides a family-centered approach to care; encompassing the parents and the sick infant as a single unit.

\section{Study subjects}

All extremely low birthweight neonates $(<1000 \mathrm{~g})$ who were admitted to the neonatal unit of the KAMC, within 3 years between January 1st, 2005 and December 31st, 2007 , constituted the target of this study $(n=117)$. These children were identified from the obstetric and delivery logbook of the maternity unit. Patients' charts were retrieved and data on maternal and neonatal demographics, clinical course and outcome (status at discharge from the unit) was extracted.

All these children were contacted to follow them up yearly till the age of six. A research coordinator was allocated for the follow up of cases via home visits in case of drop out. Every child was followed up twice by both a developmental pediatrician and a psychologist, in prescheduled visits, within the age of 3 to 6 years.

\section{Study design}

This is a retrospective/prospective cohort study. This approach is useful for exposures that have both short term and long term outcomes. It includes exposure baseline in the past (extremely low birth weight), and a follow up period (past to present to future). Data collection went in both directions. We looked through records for birth event and started to follow up these infants into the future for neurological, cognitive and educational outcomes at different ages till the age of six.

\section{Data collection and variables Retrospective phase}

A data collection sheet was used to collect the following data:

1. Maternal reasons for the prematurity; preeclampsia, intrauterine growth restriction, preterm labor, premature rupture of membranes, or multi-fetal pregnancy (multiple gestation), previous pregnancy losses, previous preterm delivery, antepartum hemorrhage and anemia.

2. Neonatal interventions, such as; the use of antenatal corticosteroids for women at risk for preterm delivery, surfactant for the prevention and treatment of neonatal respiratory distress syndrome, postnatal steroids for chronic lung disease (CLD), and modes of respiratory support for neonates with respiratory distress (conventional ventilation, high frequency ventilation, any assisted ventilation, nasal CAPA), and red cell transfusions [5].

3. Demographic and birth data: Gestational age (< 27 weeks vs $>27$ weeks), based on the date of the last menstrual period and confirmed with ultra-sonographic findings, gender, multiple birth, weight (between 450 and $600 \mathrm{~g}$ and 801-995 g), 
presentation (vertex or non-vertex), 5 min Apgar, and mode of delivery (SVD vs LSCS)

4. Outcome in terms of: death at discharge and neonatal morbidity including pneumothorax; respiratory distress, defined as the need for oxygen therapy; chronic lung disease, defined as an oxygen dependency at 36 weeks; patent ductus arteriosus, confirmed with echocardiography; episodes of sepsis, defined as clinical signs of infection with a positive blood culture; necrotizing enterocolitis (NEC); intraventricular hemorrhage (IVH) and peri-ventricular leukomalacia (PVL).

\section{Prospective phase}

Surviving children were assessed at 3 and 6 years of age, corrected for prematurity, by a developmental pediatrician and a psychologist. Neurological (neurosensory impairments and disabilities), cognitive, and educational outcomes were measured for children according to their current ages.

The pediatric assessment includes a neurological examination to determine outcomes such as cerebral palsy. Visual acuity was assessed by an optometrist. Modified Denver Developmental Screening test (DDST) for Arab Children [17] was used for assessment of developmental delay. Every child was assessed for the 4 areas of development (gross motor, fine motor/adaptive, personal/social, and language). For each area of development, if the developmental age achieved by the child is equal to the actual age, then he/she is considered normal, if exceeds the actual age, he/she is advanced, and if below the actual age, he/she is developmentally delayed. Developmental quotient (DQ) was estimated accordingly [17].

Children were considered blind if visual acuity in both eyes is assessed as worse than 6/60. Children were usually screened for major hearing loss at birth by auditory brain stem response (ABR), and at 7-8 months of corrected age by distraction testing with calibrated noise makers. Those who had not been screened or those with suspected deafness or delayed language at 2 years of age were referred again for audiological assessment.

The psychological assessment includes standardized assessments of cognitive ability, educational progress, and behavior problems. Wechsler Intelligence Scale for Children-Revised (WISC-R) [18] was applied for all ELBW children at the age of six. An Arabic, previously validated version of the scale was used [19]. Children were classified based on the IQ range into: very super (130 and above), super (120-129), high average (110-119), average (90$109)$, low average (80-89), borderline or slow learner (7079), mild (55-69), moderate (40-54), and severe intellectual disability (25-39). Figure 1 is a flowchart showing the follow up process of ELBW infants.

The approval of the IRB of the Ministry of National Guard-Health Affairs was obtained to conduct the NICU review (Ref. \# RC09/079). Consent to participate was obtained verbally from the parents/guardians of the child participants. Obtaining verbal consent was approved by the IRB.

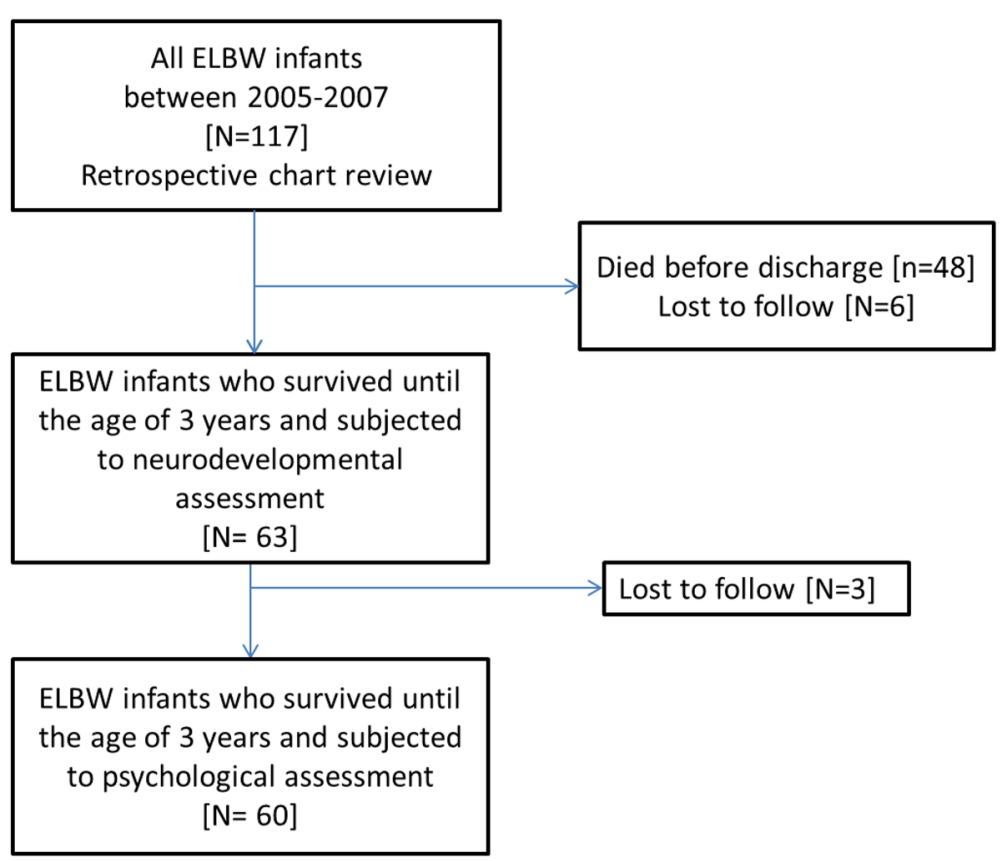

Fig. 1 Flowchart of follow up of ELBW infants from birth up to age of 6 years 


\section{Statistical analysis}

Demographics and clinical characteristics were summarized and reported for the study cohort. Continuous variables such as; age, weight at birth, GA, etc. were summarized and reported in terms of measures of central tendency (mean and median) as well as measures of variability (i.e. Standard deviation). Categorical variables such as; age gender, etc. were summarized and reported in terms of frequency and proportions. All demographics and clinical characteristics were compared across the study groups using t-test or Chi-square test for continuous and categorical variables, respectively. All results were reported in terms of difference in proportions and means, with corresponding 95\% confidence intervals (CI) and P-values. All two-way interactions between explanatory variables were tested and found to be non-significant. To test birthweight and GA as predictors of death among ELBW group, a logistic regression model was applied, adjusting for sex, mode of delivery and $5 \mathrm{~min}$ Apgar score, and the results were summarized in terms of odds ratios and their corresponding 95\% CI. Significance was considered at $p \leq 0.05$.

\section{Results}

This study was a follow up of 117 ELBW infants for the rate of survival and neurodevelopmental abnormalities. Of all ELBW infants, 69 (59\%) survived, and 48 (41\%) died, $66(56.4 \%)$ were males, with mean GA of $26.0 \pm$ 1.87 weeks, mean birth weight of $743.60 \pm 138.75 \mathrm{~g}$, and mean Apgar score at $5 \mathrm{~min}$ of $6.83 \pm 2.13$. With regard to multiple pregnancies, a total $70.1 \%$ of ELBW were the result of singleton pregnancy. Less than one-half of all ELBW (43.6\%) were delivered by cesarean section. Diabetes was prevalent in $8.5 \%$ of women, and chorioamnionitis in $7.3 \%$. The majority of women were on antenatal

Table 1 Early outcomes [death versus survival) in ELBW infants $(n=117)$ according to demographic and biological characteristics

\begin{tabular}{|c|c|c|c|c|}
\hline & Dead $(n=48,41 \%)$ & Survived $(n=69,59 \%)$ & Total $(n=117,100 \%)$ & $p$-value \\
\hline \multicolumn{5}{|l|}{ Sex } \\
\hline male & $21(31.8)$ & $45(68.2)$ & $66(56.4)$ & \\
\hline female & $27(52.9)$ & $24(47.1)$ & $51(43.6)$ & $0.021^{@}$ \\
\hline \multicolumn{5}{|l|}{ Gestational age } \\
\hline $22-23$ & $8(80.0)$ & $2(20.0)$ & $10(8.6)$ & \\
\hline $24-25$ & $24(55.8)$ & 19(44.2) & $43(36.8)$ & \\
\hline $26-28$ & $12(23.1)$ & $40(76.9)$ & $52(44.4)$ & \\
\hline $29-30$ & $4(33.3)$ & $8(66.7)$ & $12(10.2)$ & $0.002^{@}$ \\
\hline Mean \pm SD & $25.3 \pm 2.0$ & $26.4 \pm 1.7$ & $26.0 \pm 1.9$ & $0.001^{b}$ \\
\hline \multicolumn{5}{|l|}{ Birth weight } \\
\hline $450-600 \mathrm{~g}$. & $21(84.0)$ & $4(16.0)$ & $25(21.4)$ & \\
\hline $601-700 \mathrm{~g}$. & $10(47.6)$ & $11(52.4)$ & $21(17.9)$ & \\
\hline $701-800 \mathrm{~g}$. & $8(29.6)$ & 19(70.4) & $27(23.1)$ & \\
\hline $801-995 \mathrm{~g}$. & $9(20.5)$ & $35(79.5)$ & $44(37.6)$ & $<0.001^{@}$ \\
\hline Mean \pm SD & $663.0 \pm 128.6$ & $799.7 \pm 116.8$ & $743.6 \pm 138.8$ & $<0.001^{b}$ \\
\hline \multicolumn{5}{|l|}{ Type of pregnancy } \\
\hline Single & $34(41.5)$ & $48(58.5)$ & $82(70.1)$ & $0.9^{@}$ \\
\hline Multiple & $14(40.0)$ & $21(60.0)$ & $35(29.9)$ & \\
\hline \multicolumn{5}{|l|}{ Mode of delivery } \\
\hline CS & $15(29.4)$ & $36(70.6)$ & $51(43.6)$ & \\
\hline Vaginal. & $33(50.0)$ & $33(50.0)$ & $66(56.4)$ & $0.025^{@}$ \\
\hline Apgar score in 5 min. Mean \pm SD & $5.7 \pm 2.6$ & $7.6 \pm 1.3$ & $6.8 \pm 2.1$ & $<0.001^{b}$ \\
\hline \multicolumn{5}{|l|}{ Maternal factors } \\
\hline Maternal Age (mean, SD) & $28.9 \pm 7.2$ & $26.6 \pm 8.6$ & $28.0 \pm 7.2$ & $0.2^{\mathrm{b}}$ \\
\hline Diabetes & $5(10.6)$ & $5(7.2)$ & $10(8.5)$ & $0.5^{@}$ \\
\hline Premature rupture of membrane & $9(18.8)$ & $15(21.7)$ & $24(20.3)$ & $0.7^{@}$ \\
\hline Chorioamnionitis & $5(10.4)$ & $3(4.3)$ & $8(7.3)$ & $0.2^{c}$ \\
\hline Prenatal Steroids & $29(60.4)$ & $45(65.2)$ & $74(62.7)$ & $0.6^{@}$ \\
\hline
\end{tabular}

@---Chi square test, b-----student $t$ test, c-----Fisher exact test 
steroids (62.7\%). Premature rupture of membrane occurred in $20.3 \%$ of deliveries. Table 1.

Mortality rate was significantly higher among female infants $(p=0.021)$, those with lowest gestational age $(p=$ $0.002)$, those with lowest birth weight $(p<0.001)$ and those delivered vaginally $(p=0.025)$. With regard to timing of death, one-third died within 3 days after delivery (35.4\%) and one-third after 28 days (31.3\%). Table 1.

Table 2 shows the distribution of ELBW infants according to neonatal complications. CNS abnormalities

Table 2 Distribution of ELBW $(n=117)$ according to neonatal complications

\begin{tabular}{|c|c|}
\hline Complications & $\begin{array}{l}\text { Total } \\
(n=117) \\
n,(\%)\end{array}$ \\
\hline \multicolumn{2}{|l|}{ A-CNS } \\
\hline $\mathrm{IVH}$ & $75(64.1)$ \\
\hline$P V L$ & $10(8.5)$ \\
\hline Encephalopathy & $6(5.1)$ \\
\hline Seizure & $25(21.4)$ \\
\hline \multicolumn{2}{|l|}{ Retinopathy of prematurity (ROP) } \\
\hline Grade I & $45(38.8)$ \\
\hline Grade II & $6(5.2)$ \\
\hline \multicolumn{2}{|l|}{ B-CVS } \\
\hline PDA & $66(56.9)$ \\
\hline $\mathrm{CHD}$ & $4(3.4)$ \\
\hline Indomethacin & $20(17.2)$ \\
\hline Pulmonary Hypertension & $13(11.4)$ \\
\hline \multicolumn{2}{|l|}{ C-Infectious } \\
\hline Early Onset Sepsis & $11(9.5)$ \\
\hline Late Onset Sepsis & $47(40.5)$ \\
\hline Nosocomial Infection & $41(35.7)$ \\
\hline Meningitis & $4(3.4)$ \\
\hline \multicolumn{2}{|l|}{ D-Respiratory } \\
\hline RDS & $110(95.7)$ \\
\hline Surfactant & $101(87.8)$ \\
\hline Air Leak Syndrom & $1(0.9)$ \\
\hline BPD-Bronchopulmonary dysplasia & $42(36.5)$ \\
\hline Postnatal Steroid & $27(23.5)$ \\
\hline Phototherapy & $86(75.4)$ \\
\hline IPPVduration of oxygen exposure (days) & $26.6 \pm 22.5$ \\
\hline CPAPduration of mechanical ventilation (days) & $16.9 \pm 15.5$ \\
\hline Home oxygen & $3(3.5)$ \\
\hline \multicolumn{2}{|l|}{ E-GIT } \\
\hline GIT abnormalities & $2(1.8)$ \\
\hline Necrotizing enterocolitis (NEC) -stage ॥ & $31(27.0)$ \\
\hline Hyperbilirubinemia & $82(71.9)$ \\
\hline Phototherapy & $86(75.4)$ \\
\hline
\end{tabular}

were ranked according to their prevalence as follows: IVH (64.4\%), Retinopathy of prematurity (44.0\%), seizure (21.4\%) and encephalopathy (5.1\%). CVS anomalies were as follows: PDA (56.9\%), indomethacin (17.2\%), pulmonary hypertension (10.2\%), and CHD (3.4\%). Neonatal infections were in form of late onset sepsis (39.8\%), nosocomial infections (35.7\%), early onset sepsis (9.3\%), and meningitis (3.44\%). Respiratory morbidities and/or anomalies were as follows: RDS (95.7\%), surfactant (87.8\%), BPD (36.5\%) postnatal steroid (23.3\%) and Air leak syndrome (0.9\%). The mean IPPV and CPAP were $26.59 \pm 22.48$ and $16.91 \pm$ 15.45 days respectively. Infant feeding was in the form of formula (6.2\%), breast milk (4.0\%) or both (64.2\%).

Birthweight-specific mortality for all ELBW infants is shown in Fig. 2. Mortality rate decreased steadily with increasing birthweight between 450 and 995 g, ranging from $84 \%$ for $450-600 \mathrm{~g}$ infants to $22 \%$ for $801-995 \mathrm{~g}$ infants. The $50 \%$ limits of viability was that with a birthweight of $>600 \mathrm{~g}$.

The gestational age-specific mortality for all ELBW infants is shown in Fig. 3. Mortality decreased steadily through a gestational age of 28 weeks, ranging from $100 \%$ at 22 weeks. to $23 \%$ at $26-28$ weeks., and then rose slightly for infants between 29 and 30 weeks. The $50 \%$ limit of viability was that at week 25 of gestation.

As shown in Table 3, when the association of survival with birthweight and gestational age was investigated in a logistic regression model, adjusting for sex, mode of delivery and $5 \mathrm{~min}$ Apgar score, birthweight was a significant predictor of survival ( $p=0.001)$, while GA was not $(p=0.6)$.

Table 4 shows the results of pediatric and psychological assessment of the survived ELBW infants. Pediatric assessment by DDST at the age 3 years revealed developmental delays in $38.1 \%$ of children [gross motor (14.3\%), sensory adaptive (57.1\%), personal-social (42.9\%) and language (42.9\%) domains]. Other impairments were: cerebral palsy (36.2\%), delayed speech and stuttering (33.3\%), wasting (12.7\%), hyperactivity autistic behavior (6.3\%) visual disorders (6.3\%) and ADHD (3.2\%). Psychological assessment using Wechsler test for IQ at the age 6 years revealed that $10 \%$ of children were mentally retarded $[6.7 \%$ mild \& $3.3 \%$ moderate], in addition to $11.7 \%$ slow learners. The mean IQ for ELBW was within the low average range (range, 49-128, mean, 86.75).

\section{Discussion}

Survival of ELBW neonates has improved with the widespread use of exogenous surfactant agents, maternal steroids, and advancements in neonatal technologies. In our study the overall survival rate was 59\%. Mortality rate was associated with both birthweight and gestational age. Mortality rate decreased steadily with increasing birth weight between 450 and $995 \mathrm{~g}$, ranging from $84 \%$ for $450-600 \mathrm{~g}$ infants to $22 \%$ for $801-995 \mathrm{~g}$ infants. It 


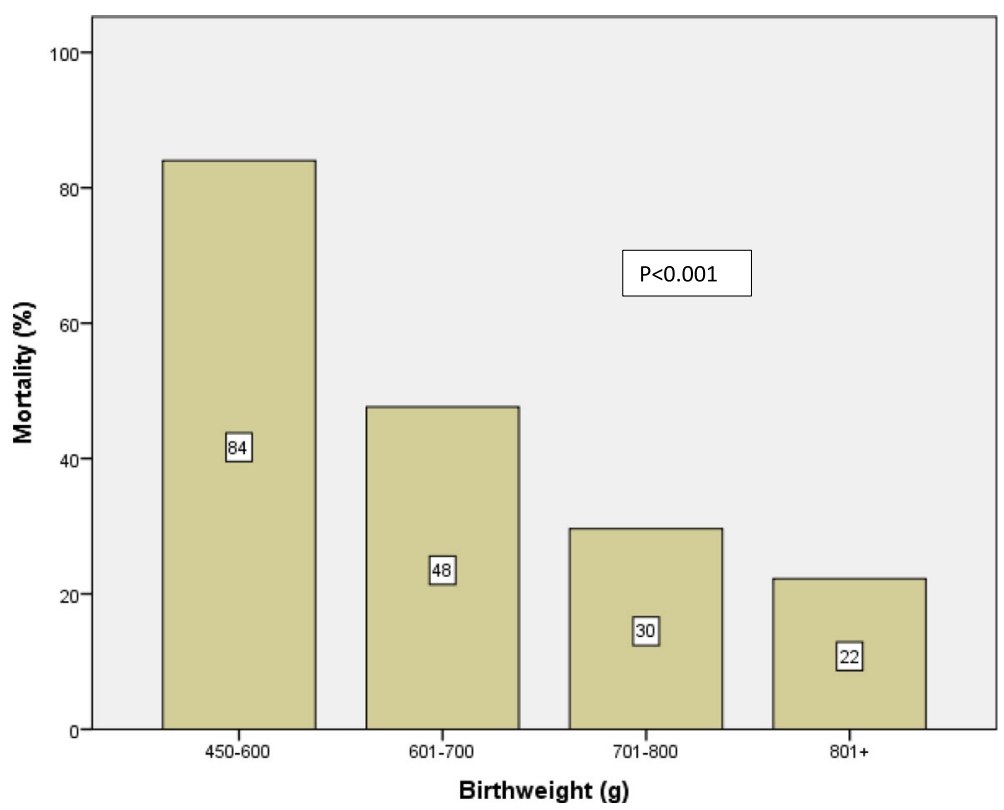

Fig. 2 Mortality rate among ELBW infants according to birthweight

decreased steadily through a gestational age of 28 weeks, ranging from $100 \%$ at 22 wks. to $23 \%$ at $26-28$ weeks, and then rose slightly for infants between 29 and 30 weeks, possibly due to the greater incidence of growth retardation and congenital malformations at later gestational ages. The Royal Women's Hospital in Australia reported death rates of $54 \%$ at 23 weeks and $32 \%$ at 24 weeks [20]. The corresponding death rate figures in our study were $84 \%$ and $48 \%$ respectively.
In Japan, where neonatal medical care was the highest quality care in the world, as reported by the WHO in 2005, the viability of ELBW infants with a $50 \%$ survival rate, were those at week 23 of gestation or with a birthweight of $500 \mathrm{~g}$ [21]. However, in our study, the $50 \%$ limits of viability were 25 weeks' gestation and $>600 \mathrm{~g}$ birthweight. It has been summarized in the literature that infants born at $<23$ weeks' gestation and $<500 \mathrm{~g}$ are too immature to survive, and provision of care for these infants is unreasonable, while

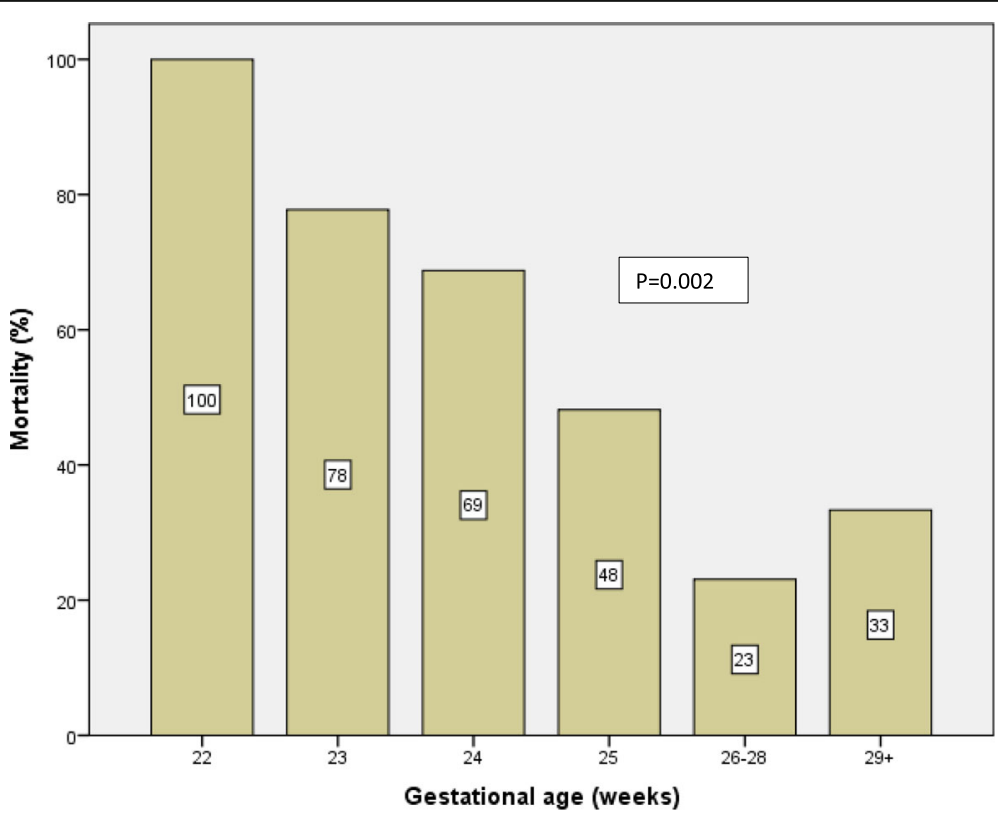

Fig. 3 Mortality rate among ELBW infants according to gestational age 
Table 3 Predictors of survival of ELBW infants

\begin{tabular}{llllll}
\hline \multirow{2}{*}{$\begin{array}{l}\text { lndependent } \\
\text { variables }\end{array}$} & $p$-value & \multirow{2}{*}{$\begin{array}{l}\text { Odds } \\
\text { ratio }\end{array}$} & & \multicolumn{2}{l}{$95 \%$ C.I. } \\
\cline { 5 - 6 } \cline { 5 - 6 } & & 2.06 & .80 & Lower & Upper \\
\hline Sex & 0.1 & .914 & .65 & 1.29 \\
Gestational age & 0.6 & 1.01 & 1.00 & 1.01 \\
Birth weight & $0.001^{*}$ & 1.03 & .36 & 2.99 \\
Mode of delivery & 0.9 & 1.68 & 1.26 & 2.25 \\
\hline Apgar score in 5 min. & $.000^{*}$ & & & &
\end{tabular}

infants who are born at $\geq 25$ weeks' gestation and with a birth weight of $\geq 600$ g are mature enough and warrant initiation of intensive care [4].

Fetal mortality rates in European countries were higher when based on a 28-week gestational age threshold compared with a $1000 \mathrm{~g}$ birthweight threshold [22]. In Japan, the predictors of survival of ELBW infants were GA at delivery, Apgar score at $5 \mathrm{~min}$, antenatal steroid and birthweight [21]. However, in our study, these predictors were birthweight and Apgar score. Fetal growth restriction is a reflection of underlying pregnancy complications [22], and a risk factor of more than $80 \%$ of fetal deaths in high-income countries, [23] and may contribute also to lower birthweights [24].

Table 4 Late outcomes of ELBW children: Results of Pediatric and psychological assessments

\begin{tabular}{lll}
\hline & $\mathrm{n}$. & $(\%)$ \\
\hline Normal children & 21 & 34.8 \\
Impairments (at age 3) $^{\mathrm{a}}$ & & \\
Developmental delay@ & 24 & 38.1 \\
Cerebral palsy & 23 & 36.2 \\
Hyperactive autistic & 4 & 6.3 \\
Blindness/amblyopia/amblyopia & 4 & 6.3 \\
Delayed speech/Stuttering & 21 & 33.3 \\
Wasting & 8 & 12.7 \\
ADHD & 2 & 3.2 \\
Psychological assessment (at age 6) & & \\
Superior & 3 & 5.0 \\
Average & 42 & 70.0 \\
Low average & 2 & 3.3 \\
Borderline (Slow learner) & 7 & 11.7 \\
Mild MR & 4 & 6.7 \\
Moderate MR & 2 & 3.3 \\
IQ verbal (mean \pm SD) & $93.5 \pm 21.8$ & \\
IQ performance (mean \pm SD) & $82.8 \pm 17.6$ & \\
IQ-Full scale (mean \pm SD) & $86.8 \pm 21.3$ & \\
\hline
\end{tabular}

a---results for 63 children, b---results for 60 children

@--Developmental delays were: gross motor (14.3\%), sensory/adaptive (57.1\%), personal/social (42.9\%), language (42.9\%)
In spite of the reduction in mortality with the use of surfactants, no significant improvement in morbidities such as; chronic lung disease, cerebral palsy, neurosensory deficits and cognitive delays, was reported among surviving infants $[9,25,26]$. In our study, pediatric assessment by DDST revealed high incidence of developmental delays, cerebral palsy, delayed speech and stuttering and wasting. The study by Marlow et al. [7] on 6-year old children born at less than 26 weeks' gestation in England revealed common cognitive and neurologic impairment with rates ranging from 22 to $34 \%$. The incidence of cerebral palsy among ELBW children in our study is extremely high (36.2\%) when compared with figures of 16 to $21 \%$ in previous studies [7, 27, 28]. However, direct comparison between our figures and figures of previous studies may be difficult because of the lack of consistency in the outcome measures, and information on the policy of intensive neonatal care and outcome measures in these institutions from which these figures were derived [7, 29, 30].

Psychological assessment using Wechsler test for IQ at the age of 6 years revealed that 10\% of children were intellectually disabled [6.7\% mild \& $3.3 \%$ moderate], in addition to $11.7 \%$ borderline or slow learners. In Anderson's study, [30] the mean IQs for ELBW children were in the average range (range, 90-109; mean, 95.5), and they were below the IQs of normal birth weight children. In our study, the mean IQ for ELBW children was below the average range (range, 49-128; mean, 86.75). These findings indicate that adverse cognitive sequelae are a more frequent outcome among such infants, and this would explain the future educational difficulties that have been reported for ELBW children [31].

\section{Limitations}

This study had some limitations and potential biases. First, is that direct comparison between our figures and figures of previous studies may be difficult because of the lack of consistency in operational definitions of the outcome measures, and lack of information on the policy of intensive neonatal care and outcome measures in these studies from which these figures were derived. Second, is that many of the possible factors that influence viability of ELBW infants were not adjusted for in the present study such as; education and adequacy of prenatal care. Maternal anemia, hydramnios/ oligohydramnios, incompetent cervix, uterine bleeding, maternal fever, premature rupture of membranes, placental abruption, other excessive bleeding, cephalopelvic disproportion, cord prolapse, and non-reassuring fetal status. Third, is that ELBW children in our study represent the outcomes of an urban tertiary perinatal center and are thus not representative of the Saudi Arabia as a whole. However, our results provide important information for public agencies and health care insurance plans and organizations [32]. 


\section{Conclusions}

In conclusion, more than one-third of ELBW died before discharge from NICU, and two-thirds of survivors had one or more neurodevelopmental and/or cognitive abnormalities during their first 6 years of life. The study showed that $50 \%$ limits of viability of ELBW infants were those at week 25 of gestation or with a birthweight of more than $600 \mathrm{~g}$. These limits are higher than those reported in other studies. However, birth weight, in our study, was the only significant predictor of survival of ELBW infants. These findings might reflect the fact that improving survival rates for the tiniest babies would result in large numbers of disabled children in the community.

Consequently, routine aggressive resuscitation of newborns at 23 weeks and/or with $<600 \mathrm{~g}$. birth weight should be approached with caution. Given the complexity of the issues, the approach to resuscitation of infants at 23 weeks must account for the perspectives of the birth mother and her family, obstetricians, and pediatricians. Thus, the process of care of ELBW needs to be revisited so as to take into consideration the findings of the present study. A multicenter study is recommended to include different types of hospitals in the kingdom and in the region, as the outcome of these infants varies from hospital to another, based on the facilities available and on the attitude of the staff of neonatal intensive care units, whether they are proactive or selective in management of those ELBW infants.

\section{Abbreviations}

ABR: Auditory brain stem response; ADHD: Attention deficit hyperactivity disorder; BPD: Bronchopulmonary dysplasia; CHD: Congenital heart disease; CLD: Chronic lung disease; CNS: Central nervous system; CVS: Cardiovascular system; DDST: Denver developmental screening test; DQ: Developmental quotient; ELBW: Extremely low birth weight; GA: Gestational age; GIT: Gastrointestinal tract; IQ: Intelligent quotient; IRB: Institutional Review Board; IVH: Intraventricular hemorrhage; KAMC: King Abdulaziz Medical city; LSCS: Lower segment cesarean section; MNG-HA: Ministry of National Guard-Health Affairs; MR: Mental retardation; NEC: Necrotizing enterocolitis; NICU: Neonatal intensive care unit; PDA: Patent ductus arteriosus; PVL: Periventricular Leukomalacia; RDS: Respiratory distress syndrome; SD: Standard deviation; SVD: Spontaneous vaginal delivery; WHO: World Health Organization; WISC-R: Wechsler Intelligence Scale for Children-Revised

\section{Acknowledgements \\ This study was initiated and supported by King Abdullah International Medical Research Center, King Saud bin Abdulaziz University for Health Sciences, Riyadh, Saudi Arabia. The authors would like to thank the Research Office and the Institutional Review Board for their tremendous support. The final draft of the manuscript was English language edited by Macmillan Science communication.}

\section{Availability of data and materials}

Most of the data supporting our findings is contained within the manuscript, and all others, excluding identifying/confidential patient data should, will be shared upon request.

\section{Authors' contributions}

MAA and MAR contributed to concept development, manuscript preparation and final writing, MAR and SS and WAA contributed to concept development and data collection, WAA contributed to concept development and manuscript finalization, and MAA and MAR contributed to research proposal writing, data collection, analysis and interpretation, and manuscript drafting. All authors read and approved the final manuscript.

\section{Competing interest}

The authors declare that they have no competing interests.

\section{Ethics approval and consent to participate}

This study was approved by the institutional review board of the MNG-HA in Riyadh, Saudi Arabia (Ref. \# RC09/079). Consent to participate was obtained from the parents/guardians of the child participants, and the IRB approved obtaining it verbally.

\section{Consent for publication}

Not applicable

\section{Publisher's Note}

Springer Nature remains neutral with regard to jurisdictional claims in published maps and institutional affiliations.

\section{Author details}

${ }^{1}$ Research Training and Development Section, King Abdullah International Medical Research Center, King Saud bin-Abdulaziz University for Health Sciences - Ministry of National Guard-Health Affairs, Riyadh, Saudi Arabia. ${ }^{2}$ King Abdulaziz Medical City, King Saud bin-Abdulaziz University for Health Sciences, Ministry of National Guard-Health Affairs, Riyadh, Saudi Arabia.

Received: 7 February 2018 Accepted: 8 August 2018

Published online: 22 August 2018

\section{References}

1. Lorenz JM. The outcome of extreme prematurity. Semin Perinatol. 2001;25: 25348-59.

2. Doyle LW. The Victorian infant collaborative study group. Neonatal intensive care at borderline viability. Is it worth it? E Hum Develop. 2004;80:103-13.

3. Kaiser JR, Tilford JM, Simpson PM, Salhab WA, Rosenfeld CR. Hospital survival of very-low-birth-weight neonates from 1977 to 2000. J Perinatol. 2004:24:343-50.

4. Seri I, Evans J. Limits of viability: definition of the gray zone. J Perinatol. 2008:28:54-8

5. American Academy of Pediatrics: "Trends in Mortality and Morbidity for Very Low Birth Weight Infants, 1991-1999." Pediatrics Volume 10, Issue 1 (2002 https://doi.org/10.1542/peds.110.1.143Wood NS,

6. Marlow N, Costeloe K, Gibson AT, Wilkinson AR. Neurologic and developmental disability after extremely preterm birth. EPICure study group. N Engl J Med. 2000;343:378-84

7. Marlow N, Wolke D, Bracewell MA, Samara M, the EPICure Study Group. Neurologic and developmental disability at six years of age after extremely preterm birth. N Engl J Med. 2005:352:71-2.

8. Marlow N, Wolke D, Bracewell MA, Samara M. Neurologic and developmental disability at six years of age after extremely preterm birth. $N$ Engl J Med. 2005;352:9-19.

9. Hack M, Taylor HG, Drotar D, Schluchter M, Cartar L, Andreias L, WilsonCostello D, Klein N. Chronic conditions, functional limitations, and special health care needs of school-aged children born with extremely low-birthweight in the 1990s. JAMA. 2005:294:318-25.

10. Anderson P, Doyle LW, the Victorian Infant Collaborative Study Group. Neurobehavioral Outcomes of School-age Children Born Extremely Low Birth Weight or Very Preterm in the 1990s. JAMA. 2003;289(24):3264-72. https://doi.org/10.1001/jama.289.24.3264.

11. Chervenak FA, McCullough LB, Levene MI. An ethically justified, clinically comprehensive approach to peri-viability: gynecological, obstetric, perinatal and neonatal dimensions. J Obstet Gynaecol. 2007;27:3-7.

12. Streiner DL, Saigal S, Burrows E, Stoskopf B, Rosenbaum P. Attitudes of parents and health care professionals toward active treatment of extremely premature infants. Pediatrics. 2001;108:152-7.

13. Prenatal Audit. In: Ed Dunn PM, Mcllwaine G, editors. A report produced for the European association of perinatal medicine, vol. 39: 1996; The Parthenon Publishing Group Ltd, Casterton Hall Carnforth Lancs LA6 2LA United Kingdom. http://www.parthpub.com

14. Nishida $\mathrm{H}$. The viability limit of gestation for the fetus and premature neonates. Asian Med J. 1992;35:487-94. 
15. Special considerations. In: Braner D, Kattwinkel J, Denson S, Zaichkin J, editors. Textbook of Neonatal Resuscitation. 4th ed. Elk Grove Village, IL: American Heart Association, American Academy of Pediatrics, c2000, Libraries Australia; 2007. p. 7-19.

16. Al-Alaiyan S, Al-Abdi S, Alallah J, Al-Hazzani F, AlFaleh K. Pre-viable newborns in Saudi Arabia: where are we now and what the future may hold? Curr Pediatr Rev. 2013;9:4-8.

17. Abolfotouh MA, Nofal LM, Nosseir SA. A simplified method of developmental assessment of infants and preschool children and some associated findings. Alexandria Journal of Pediatrics. 1990;4:417-30.

18. Wolke D, Ratschinski G, Ohrt B, Riegel K. The cognitive outcome of very preterm infants may be poorer than often reported: an empirical investigation of how methodological issues make a big difference. Eur J Pediatr. 1994;153:906-15.

19. Ibrahim ER (ed.). Denver Developmental Screening Test. Manual. Department of Psychology, King Saud University, Riyadh, Saudi Arabia, National Guard Printing Press, 1991.

20. Batton DG, DeWitte DB, Espinosa R, Swails TL. The impact of fetal compromise on outcome at the border of viability. Am J Obstet Gynecol. 1998;178:909-15.

21. Ogawa M, Matsuda Y, Kanda E, Konno J, Mitani M,Makino Y, Matsui H. Survival Rate of Extremely Low Birth Weight Infants and Its Risk Factors: Case-Control Study in Japan. Obstetrics and Gynecology Volume 2013, Article ID 873563, 6 pages.

22. Mohangoo AD, Blondel B, Gissler M, Velebil P, Macfarlane A, Zeitlin J. The Euro-Peristat Scientific Committee. International Comparisons of Fetal and Neonatal Mortality Rates in High-Income Countries: Should Exclusion Thresholds Be Based on Birth Weight or Gestational Age? PLoS One. 2013;8(5) https://doi.org/10.1371/journal.pone.0064869

23. Frøen JF, Gordijn SJ, Abdel-Aleem H, Bergsjø P, Betran A, et al. Making stillbirths count, making numbers talk - issues in data collection for stillbirths. BMC Pregnancy Childbirth. 2009;9:58.

24. Chard T. Does the fetus lose weight in utero following fetal death: a study in preterm infants. BJOG. 2001;108(11):1113-5.

25. Anderson P, Doyle LW. Neurobehavioral outcomes of school-age children born extremely low birth weight or very preterm in the 1990s. JAMA. 2003; 289(24):3264-72. https://doi.org/10.1001/jama.289.24.3264.

26. Subramanian KNS. Extemely Low Birth Weight Infant." Medscape Pediatrics: Cardiac Disease and Critical Care Medicine (2014). https:// emedicine.medscape.com/article/979717-overview?cc=aHROcDovL2VtZWRp Y2luZS5tZWRzY2FwZS5jb20vYXJ0aWNsZS85Nzk3MTctb3ZIcnZpZXC\%3D \&cookieCheck=1. Accessed 12 Aug 2018.

27. Finnstrom O, Gaddlin PO, Leijon I, Samuelsson S, Wadsby M. Very-low-birthweight children at school age: academic achievement, behavior and self-esteem and relation to risk factors. J Matern Fetal Neonatal Med. 2003;14:75-84.

28. D'Angio CT, Sinkin RA, Stevens TP, et al. Longitudinal, 15-year follow-up of children born at less than 29 weeks' gestation after introduction of surfactant therapy into a region: neurologic, cognitive, and educational outcomes. Pediatrics. 2002;110:1094-102.

29. Hack M, Fanaroff AA. Outcomes of children of extremely low birthweight and gestational age in the 1990's. Early Hum Dev. 1999;53:193-218.

30. Emsley HC, Wardle SP, Sims DG, Chiswick ML, D'Souza SW. Increased survival and deteriorating developmental outcome in 23 to 25 week old gestation infants, 1990-4 compared with 1984-9. Arch Dis Child Fetal Neonatal Ed. 1998;78:F99-F104.

31. Saigal $S$, den Ouden L, Wolke D, et al. School-age outcomes in children who were extremely low birth weight from four international populationbased cohorts. Pediatrics. 2003;112:943-50.

32. Martin JA, Hamilton BE, Sutton PD, Ventura SJ, Menacker F, Munson ML. Births: final data for 2002: National Vital Statistics Report 52 no. 10. National Center for Health Statistics: Hyattsville, Md; 2003.

\section{Ready to submit your research? Choose BMC and benefit from:}

- fast, convenient online submission

- thorough peer review by experienced researchers in your field

- rapid publication on acceptance

- support for research data, including large and complex data types

- gold Open Access which fosters wider collaboration and increased citations

- maximum visibility for your research: over $100 \mathrm{M}$ website views per year

At $\mathrm{BMC}$, research is always in progress.

Learn more biomedcentral.com/submissions 